University of Windsor

Scholarship at UWindsor

OSSA Conference Archive

OSSA 4

May 17th, 9:00 AM - May 19th, 5:00 PM

\title{
Strategic Maneuvering with the Burden of Proof
}

Frans $\mathrm{H}$. van Eemeren

Univ. of Amsterdam

Peter Houtlosser

Univ. of Amsterdam

Follow this and additional works at: https://scholar.uwindsor.ca/ossaarchive

Part of the Philosophy Commons

van Eemeren, Frans H. and Houtlosser, Peter, "Strategic Maneuvering with the Burden of Proof" (2001). OSSA Conference Archive. 24.

https://scholar.uwindsor.ca/ossaarchive/OSSA4/papersandcommentaries/24

This Paper is brought to you for free and open access by the Conferences and Conference Proceedings at Scholarship at UWindsor. It has been accepted for inclusion in OSSA Conference Archive by an authorized conference organizer of Scholarship at UWindsor. For more information, please contact scholarship@uwindsor.ca. 
Title: $\quad$ Strategic Maneuvering with the Burden of Proof

Authors: Frans H. van Eemeren \& Peter Houtlosser

Response to this paper by: Joseph Wenzel

(c) 2001 Frans H. van Eemeren \& Peter Houtlosser

\section{The pragma-dialectical approach to argumentation}

According to Johnson (1998), to engage in the practice of argumentation is "to enter argumentative space." The problem with this endeavor is that different theoreticians see this space in different ways. We, from our point of view, distinguish between two general metaperspectives in the study of argumentation: a dialectical perspective focusing on critical debate, and a rhetorical perspective concentrating on the most appropriate means of persuasion in a certain context. This distinction, of course, corresponds with the well-known Aristotelian division.

For Aristotle, dialectic and rhetoric were two complementary arts, whose relation he characterizes with the term antistrophos. As Leff (2000) rightly observes, dialectic and rhetoric have by no means proven to be "fixed entities"; they should rather be seen as "evolving disciplines, defined and redefined" in the course of history. Their identity, structure, function and relationship have changed continuously and the division has even become "ideological" (Toulmin 1997). Due to the successes of the exact sciences, dialectic gained the upper hand while rhetoric became marginalized as a mere doctrine of stylistics, which was left to the humanities. In our view, it is obvious that since dialectic became part of a 'de-dialectified' and formalized logic there is a yawning conceptual and communicative gap between the two disciplines (van Eemeren and Houtlosser 1999).

During the past three decades, in the study of argumentation a remarkable revival has taken place of both dialectic and rhetoric. There is at the same time some debate about their status and mutual relationship. Johnson, for one, is not sure about whether dialectic is a "free-standing discipline"; he seems inclined to assign dialectic a supplementary role. Leff sees a separate place in argumentation theory for dialectic beside rhetoric. Where these authors both perceive dialectic in the first place as an addition to logic or rhetoric, we view dialectic as the heart of the study of the argumentative process of critically testing opinions (van Eemeren and Grootendorst 1984; van Rees 2000).

By making use of dialectical insight taken from critical rationalism and dialogue logic, van Eemeren and Grootendorst (1984) have developed a procedure for resolving differences of opinion by testing standpoints critically. In agreement with Barth and Krabbe's (1982) requirements of problem-validity and conventional validity, no moves are allowed that are inconsistent, or that in any other way interfere with the resolution process, or that do not cohere with the point of departure as defined by the arguers. We favor a pragma-dialectical approach that situates argumentation in a pragmatic context of instrumental action within a dialectical procedural framework. Among the theoretical tools for substantiating the pragmatic dimension of this approach are speech act theory, discourse analysis, and the Gricean theory of practical rationality.

The dialectic and the pragmatic dimensions of our approach are jointly given shape by four meta-theoretical principles. Unlike Rescher (1977) and Biro and Siegel (1992), who define argumentation in their epistemological approaches as "plausible justification of theses" and 
"reasonable justification of beliefs," and following the principle of functionalization, pragmadialecticians conceive argumentation as a complex speech act aimed at justifying or refuting a standpoint to convince the interlocutor of the acceptability or unacceptability of that standpoint.

By relying on commitments ensuing in argumentative discourse from what has been said explicitly or implicitly, thus following the principle of externalization, we find ourselves in agreement with Mackenzie and Staines. They also argue that an argument "directly affects, not belief or opinion, but public commitment" $(1999,35)$. As Hamblin observed earlier $(1970,264)$, our saying commits us, whether we believe what we say or not. We also agree with Hamblin (1970, 16-17) that commitments can be incurred simply by putting on the appropriate linguistic performance - in our terms, by performing the appropriate speech act. In the critical discussion we envisage, the participants' aim is to convince each other by making use of their own and each other's commitments. ${ }^{2}$

Walton and Krabbe $(1995,9)$ note that a dialogue is enabled to move forward because the participants are willing to take on commitments in a collaborative way. This observation captures the mutual coordination that, following the principle of socialization, is expressed in the way we situate the performance of speech acts in a dialogical context where the need for anticipating and responding to the (presumed) reactions of the other party determines the progress of the discourse. By indicating "agreement or disagreement with a preceding remark of the other speaker," the participants build up their commitment stores. As Walton and Krabbe rightly observe, to know what a party is committed to should be equivalent to knowing what that party should do, or not do, to live up to this commitment $(1995,17)$. There must therefore be rules of procedure for performing speech acts that specify, for each discussion stage, under which conditions certain commitments are incurred or deleted from a participant's commitment store, from the beginning of the discussion in the confrontation stage to its termination in the concluding stage. In establishing procedural rules for resolving a difference of opinion, we provide, following the principle of dialectification, standards for the conduct of argumentative discourse that regulate critical interaction (van Eemeren and Grootendorst 1984, 1992).

In this way, we are in perfect agreement with Rescher's (1977) recommendation to move "from the plane of the [...] descriptive and ontological to that of the [...] regulative and methodological." Our dialectical standards are more inclusive, and also more differentiated, than the logical standard of formal validity and the preservation of truth (van Eemeren and Grootendorst 1992). What is dialectically sound is what can be maintained in a party's commitment store without leading to any justified accusation of logical or pragmatic inconsistency. With Barth and Krabbe (1982), we are among those who speak of a reasonable result of a discussion when this result has been reached by arguing ex concessis. In other words,

\footnotetext{
${ }^{1}$ We prefer to use the terms 'tenability' or 'acceptability,' to keep the basic theoretical apparatus free from epistemic associations. Surprisingly, coming from anti-relativists, Biro and Siegel claim that "an argument aims at, and a good one succeeds in, leading an inquirer or an audience from some proposition(s) whose truth or justifiedness they accept to others whose truth or justifiedness they will see themselves as having good reasons to accept on its basis" (1992, 92, our italics, vEH).

${ }^{2}$ Hamblin's idea of a commitment-store, which is similar to Lorenzen's set of concessions, and the accompanying commitment rules, are an invaluable addition to this way of theorizing: they make it possible to determine what each participant is committed to at each particular discussion stage. This is exactly the kind of externalization we are aiming for.
} 
we opt for a pragmatic way out of the Münchhausen trilemma (Albert 1975): our pragmatic angle warrants us to stop the process of argumentation at the point where acceptance by the other party is assured.

\section{Strategic maneuvering in argumentative discourse}

Argumentative discourse can only be critically evaluated in a theoretically justified way if the discourse has first been adequately analyzed. ${ }^{3}$ This requires a method of analysis that is systematic and leads to general and sustained pronouncements rather than merely ad hoc observations. Starting from the pragma-dialectical point of departure, the analysis of argumentative discourse can be envisioned as a methodical reconstruction of the process of resolving the difference of opinion contained in the discourse.

Our method of analysis is to lead to an 'analytic overview' attuned to enabling a sound critical evaluation. The model of a critical discussion can serve as a heuristic instrument for reconstructing the discourse in such a way that it becomes clear which function the various speech acts fulfil and which commitments they create. In a reconstruction of a discourse as a manifestation of a critical discussion it is assumed that the arguers aim to resolve their dispute on the merits. At the same time, however, it may be assumed that they will be intent on having their own standpoints accepted. This means that on the one hand they are committed to objectives and obligations of a dialectical kind, and on the other hand they have aims and considerations that are to be understood rhetorically. While dialectical obligations have to do with the argumentative procedures that further an abstract ideal of rationality in critical discussion, rhetorical considerations are more pragmatic and relate to the contextual adjustment of argumentation to the people who are to be convinced and their discursive standards. In order to develop a method of analysis that is more refined, and gives a more accurate account of the exigencies of argumentative reality, we intend to supplement our current tools for reconstruction with additional pragmatic tools by incorporating insights from classical and modern rhetoric.

As Wenzel (1980) observed two decades ago, "from the standpoint of rhetoric, a good argument is an effective one." This does not mean, however, that viewed from a rhetorical perspective anything goes as long as it is persuasive. Aristotle did not define rhetoric in terms of persuasive effect, but as the faculty for observing in any given case the available means of persuasion. Leff (2000) emphasized that "this position implies a difference between using the art properly and achieving a specific outcome." In his opinion, "rhetorical art can sustain intrinsic norms of its own." Beside the dialectical obligation to abide by the rules of critical discussion, Krabbe (1999) also distinguishes an obligation "to try to do well in the dialogue."4

In the end, as Leff (2000) puts it so well, "rhetoric's effort to achieve 'effective persuasion' must be disciplined by dialectical rationality." Conversely, we would like to claim that there is nothing inconsistent about attempting to resolve a difference of opinion and trying to do so in one's own favor, even though there is indeed a potential discrepancy between pursuing

\footnotetext{
${ }^{3}$ Such a critical evaluation presupposes that ordinary arguers will, at least in principle, be inclined to comply with standards like those of a critical discussion (van Eemeren, Meuffels and Verburg 2000).

${ }^{4}$ Krabbe thinks that this might be a "dialectical obligation," but in our opinion it typically represents a norm of a rhetorical nature that is implemented in a dialectical view of argumentative discourse.
} 
dialectical objectives and rhetorical aims. This potential discrepancy gives rise to the management of the discourse that we call strategic maneuvering, which is aimed at making the strongest possible case while at the same time avoiding any moves that are clearly unreasonable (van Eemeren and Houtlosser 1998, 1999, 2000a, 2000b). In a great many cases, whether it is successful or not the maneuvering is in perfect agreement with the rules for critical discussion and may count as acting reasonably. As a rule, strategic maneuvering is at least aimed at avoiding an open violation of these critical standards. Even arguers who momentarily let the aim of getting their own position accepted prevail will strongly attempt to keep up the appearance of being committed to the critical ideal of reasonableness. They will still display what Johnson (2000) calls "manifest rationality."

Because the kind of advantages that can be gained depends on the dialectical stages, the presumed rhetorical objectives of the participants must be specified according to stage. As we have explained in earlier papers, strategic maneuvering can take place in making an expedient selection from the options constituting the topical potential associated with a particular discussion stage, selecting a responsive adaptation to audience demand, and exploiting the appropriate presentational devices. Given a certain difference of opinion, speakers or writers will choose the material they can most appropriately deal with, make the moves that are most acceptable to the audience, and employ the most effective presentational means. Although these three aspects, which run parallel to important classical areas of interest - topics, audienceorientation, and stylistics - can be distinguished analytically, in actual practice they will usually work together. 5

\section{The 'burden of proof' as a procedural concept}

The way in which in an argumentative exchange the burden of proof is divided sets the stage for the interactional patterns that may develop in the discourse. The concept of 'burden of proof' is therefore crucial in the analysis of argumentation and consequently in argumentation theory. In particular since the involvement of Richard Whately, it has received a lot of attention. We shall explain our pragma-dialectical perspective by answering a number of pertinent questions, starting with the fundamental question why a division of the burden of proof is necessary.

In our view, a division of the burden of proof is necessary in the first place for methodological reasons. Like Rescher (1977), we consider the burden of proof a procedural concept, which serves the critical rationalist purpose of testing the tenability of a standpoint by carrying through the appropriate testing procedures as systematically, perspicuously, efficiently and thoroughly as required. A critical discussion aimed at resolving a difference of opinion concerning the acceptability of a standpoint can only be resolved if the division of the burden of proof is clear and the parties comply with this division. We therefore implemented the principle of socialization in the opening stage of the critical discussion by regulating the mutual

\footnotetext{
${ }^{5}$ It is often wrongly assumed that audience adaptation is the overriding, if not the only, characteristic of rhetoric. Rhetoric is then without any further ado equalized with giving in to audience demand. There is also a tradition in which the use of presentational devices is taken to be the main characteristic of rhetoric. Rhetoric is then primarily viewed as stylistics. In fact, topical selection could just as well be seen as the general umbrella characteristic of rhetoric. In the latter case, rhetoric would be aptly described as the art of finding the appropriate loci of persuasion. In our view, none of these one-sided conceptions of rhetoric does justice to the intricate relationship inherent in any form of adequate strategic maneuvering.
} 
coordination of the critical procedure in a "burden of proof rule" (van Eemeren and Grootendorst 2002) that regulates how the onus probandi with regard to a standpoint is distributed in the most perspicuous way. In this way, the concept of "burden of proof" serves the "division of labor of argumentation" (Rescher 1977). In terms of formal dialectics, one could say that only if the participants are taking on commitments in a collaborative way can the dialogue move forward (Walton and Krabbe 1995, 9). In attributing a purely methodological status to the concept of burden of proof, we differ from others who appear to attribute epistemological, ideological, ethical or even moral qualities to assuming the burden of proof.

It is clear that there should be a division of the burden of proof. The next question, however, is: a burden of proof for what? In answering this question, we regard argumentative discourse as consisting of the performance of speech acts, each type of speech act creating its own commitments, and only some specific commitments creating a burden of proof. From the perspective of a critical discussion, in assertive speech acts - or speech acts to be reconstructed as assertives - two types of commitment are to be distinguished, which have different procedural consequences. First, there are assertives advancing a standpoint, or an argument that in the course of the discussion becomes a substandpoint. These assertives create the specific commitment that constitutes a burden of proof. Second, there are assertives performed to establish a starting point for the discussion. These assertives create commitments that can be used in the argumentation and concluding stages of the discussion. They have the same function as the formal dialectical concessions, albeit that in a critical discussion such concessions are made by both parties and the commitments they create can be used in both defending and attacking a standpoint. Since these assertives can only serve as a starting point when - and because - they are mutually agreed upon, they do not carry a burden of proof.

What does having a burden of proof involve? In the pragma-dialectical perspective the burden of proof for a (sub)standpoint is the obligation to defend the standpoint once challenged to do so, i.e., to justify or refute the opinion expressed in the standpoint. This implies an obligation to give an adequate rejoinder to the critical response of the other party, i.e., to argue the case concerned as thoroughly and extensively as the antagonist's criticisms require. Where Johnson $(1998,1999)$ includes dealing with contradictory or otherwise alternative standpoints in the protagonist's burden of proof, the presence of such alternative standpoints makes the dispute in our approach "mixed" - or even "multiple." Then similar conditions for a burden of proof apply to the other party. According to our principle of externalization, only those objections that are somehow advanced in the discussion, whether explicitly, implicitly or indirectly, need to be dealt with by the protagonist.

Under which conditions is there a burden of proof? The obligation to defend a standpoint always applies and holds fully until the protagonist has complied with his obligation to defend his standpoint or has retracted the standpoint. There are, nevertheless, some practical restrictions. Both in a non-mixed and in a mixed dispute, maintaining the burden of proof does not make sense when the protagonist has earlier defended his standpoint successfully against the same antagonist starting from the same point of departure. Starting a critical discussion is also a waste of time when no joint point of departure can be established. ${ }^{6}$

\footnotetext{
${ }^{6}$ We agree with Rescher (1977) that it should always be possible to refer to a "common ground" that determines "what is to count as evidence." We do not agree, however, that this common ground is necessarily "impartially fixed": we leave it to the parties involved to choose their own point of departure.
} 
Who has the burden of proof? Which task is assigned to whom is in our approach a matter of procedural agreement concerning the division of labor in a critical discussion. Unless it is explicitly agreed otherwise, the burden of proof is on the side of those whose standpoints are challenged by the other party. Throughout the discussion, the division of the burden of proof can, at certain points, become more diversified. As Walton and Krabbe observe, "some commitments are initially set or undertaken, and other commitments are [...] incurred along the way" (1995, 50). In our approach, the latter comprise both the commitment to defend the reasons in defense of the standpoint that have been challenged, and thus have become substandpoints, and also the commitment to reply to the critical reactions advanced in challenging the argument schemes that connect these reasons with the standpoint at issue. Rescher (1977) and Walton (1988) proclaim that the protagonist's advancing a prima facie argument for his initial standpoint shifts the burden of proof to the other party. In our view, this amounts to a transfer of argumentative duties from one party to the other: a "shift of initiative" rather than a "shift of burden of proof." In a non-mixed dispute it is up to the antagonist to ask pertinent critical questions regarding the protagonist's argument; in a mixed dispute the other party's attack will be more severe.

In a non-mixed dispute, only one party has advanced an initial standpoint and there is only a burden of proof for this party. In a mixed dispute, where two parties have advanced contrary standpoints, each party has a burden of proof for his own standpoint. The problem is: in which order are the standpoints to be defended? And what is the rationale of the "priority principle" that is to be applied? Hamblin takes a simple view: "He who asserts must prove,' in that 'Statement S // Why S?' clearly puts the onus on the first speaker" (1970, 274). In our view a somewhat more accommodating approach is needed, because there are cases in which the one party has advanced a standpoint that is clearly simpler or faster to defend than the standpoint advanced by the other party. The least difficult defense should then take priority. The question, however, is how it can be determined which standpoint is easiest to defend.

In Whately's view, the burden of proof lies on the side of him who would dispute a "presumption," so the issue of who should start the defense is decided in favor of the party whose standpoint has the highest degree of presumption. This policy, however, does not solve our procedural problem. In a mixed dispute both of the contrary standpoints are in need of defense, so that neither of them could serve as a presumption. Then only the procedural and material starting points that are agreed upon or taken for granted in the opening stage of the critical discussion have the function of presumption, at least for the duration of the discussion. ${ }^{8}$

In epistemological approaches, such as Rescher's (1977), the crucial issue is "how readily the thesis could make its peace within the overall framework of our cognitive commitments." Presumption is then conceived as an epistemic category: the one assertion has presumption because it is more plausible than the other. According to Rescher, the conception of burden of proof is "correlative" with that of a presumption. In his opinion, "in most probative contexts, there is a standing presumption in favor of the usual, normal, customary course of things," which he characterizes as "the cognitive status quo." When Rescher refers to "the usual course of things" in plausible assessment, his words seem to echo those of Perelman and Olbrechts-Tyteca

\footnotetext{
${ }^{7}$ In his system for dealing with (mixed) disputes, Hamblin $(1970,274)$ also replaces the concept of burden of proof by the "somewhat simpler concept of initiative."

${ }^{8}$ Barth and Krabbe (1982) take a similar approach.
} 
in their Nouvelle rhétorique (1958). In our opinion, the main problem remains that in actual practice people often tend to disagree as to what exactly is to be considered as the status quo. ${ }^{9}$

Our approach accords well with the pragmatic view of Ullman-Margalit (1983) that the issue is not so much concerned with "ascertaining the facts as with proceeding on them". Her procedural consideration concerning the "comparative convenience with which the parties can be expected to produce pertinent evidence" has to do with the question "of what presumption will be the most useful to adopt as an initial step in the process of deliberation [...], quite apart from the question whether the conclusion to which [this] adoption [...] points is likely to be true." 10

Van Eemeren and Grootendorst (1992) pointed out that in a mixed dispute the issue of which standpoint can be most easily defended can be determined by appealing to the principle of "fairness." In civil law the fact that a "negative fact" is often harder to prove than a concrete incident is acknowledged along similar lines. In practice, however, the principle of fairness can only be used if the parties agree on its application.

Another important question to be answered is: what means can be used to meet the burden of proof? In to our pragma-dialectical approach, the only means of meeting the burden of proof is advancing argumentation. The argumentation can be single, but, depending on the further critical reactions to the use of a particular argument scheme and the counter-arguments of the other party, it may also become multiple, coordinatively compound, subordinatively compound or some combination of those.

In advancing argumentation, the protagonist can make good use of the starting points that have been established in the opening stage of the discussion. Two kinds of distinctions can be made with respect to these starting points. First, there is a distinction between starting points that consist of material commitments (premises) and starting points that consist of formal commitments (discussion rules). Second, there is a distinction between explicit starting points and implicit starting points. The explicit starting points are mutually agreed upon; as avowed commitments, they may not simply be revoked. The explicit starting points have a status similar to the propositional commitments that Hamblin (1970), Barth and Krabbe (1982) and Walton and Krabbe (1995) call "concessions." The implicit starting points are assumed to be inherent in the discussion context; as contextual commitments, they are liable to rejection but must be maintained if they have successfully passed the appropriate "intersubjective identification

\footnotetext{
${ }^{9}$ Whately already detected a presumption in favor of existing institutions, "on the ground that since a change is not good in itself, he who demands a change should show a cause for it." "If Bishop Whately were to revise his Elements of Rhetoric for a late twentieth-century audience," Gaskins writes one and a half century later (1992: 4546), "he would no doubt sadly inform us that, in public debate, the old presumption in favor of "every existing institution' has now been shifted. The burden of proof no longer falls on 'him who proposes an alteration,' but rather on anyone who dares to suggest that existing institutions are doing their job. Whately's conservative presumption, now blatantly reactionary, has been seriously challenged by its rhetorical counterpart: the increasingly radical presumption of institutional failure." This explains why Goodnight (1980) feels there should be room for a "liberal presumption."

${ }^{10}$ Although adopting a presumption clearly prejudges an issue, it may in Ullman-Margalit's view be seen as rational in a twofold sense: in any particular instance the presumption is open to rebuttal, and the bias it promotes is independently justifiable. In pragma-dialectical terms, the former would mean that a starting point can be revoked; this, however, is only allowed when it can be shown by offering counter-evidence that this starting point is, after all, not acceptable. The latter would mean that institutional or other contextual support must be available.
} 
procedure" instigated by the party who does not accept them at face value (van Eemeren and Grootendorst 2001). ${ }^{11}$

The rationale for using certain starting points is in the pragma-dialectical approach a pragmatic one. ${ }^{12}$ A starting point is acceptable if it is by intersubjective agreement accepted as such by the parties, irrespective of whether the reason for their acceptance is epistemological, ethical, ideological, juridical, esthetic or other. As we have emphasized before, argumentation does not deal only with matters of truth and plausibility but also with policy matters, moral issues, etc. An epistemological perspective such as Rescher's can therefore at best cover only part of argumentative reality, thus excluding an abundance of important issues from "argumentative space."

When has the burden of proof been discharged? In practice, one can sometimes get rid of the burden of proof because of incidental circumstances such as the antagonist abandoning his doubt without any critical consideration - or the death of the protagonist. The burden of proof has only really been discharged when the standpoint has been sufficiently defended in the critical discussion and can be maintained while the opposition has to be withdrawn. A well-defined procedure is required in order to achieve this result in an orderly fashion and in a finite number of steps.

Like Rescher, we find it necessary that in what we call the opening stage of the discussion the parties jointly determine what the rules are. ${ }^{13}$ Unlike in Rescher's approach, in the pragmadialectical approach the rationale of the rules lies in their "problem-validity" for the purpose of critically testing the acceptability of standpoints. Among the pragma-dialectical rules are those for the use and the correct application of argument schemes and for critically responding to argument schemes. However complex may be the structure of the argumentation - due to the critical reactions - every separate argument is connected with the main standpoint or a substandpoint by means of a certain argument scheme, and needs therefore to be tested on its own merits. In pragma-dialectics, this testing takes place in accordance with a fixed procedure. A crucial role in the testing procedure is played by the critical questions associated with the argument scheme used by the protagonist. These questions differ for causal argumentation, comparison argumentation, and symptomatic argumentation. Only by responding to all relevant critical questions, by adding a (subordinative, coordinative or multiple) extension to the argumentation, can the protagonist discharge his (possibly cumulated) burden of proof. The pragma-dialectical critical questions are not identical with the "objections" an arguer should

${ }^{11}$ Our contextual commitments are akin to Walton and Krabbe's (1995) "veiled" or dark-side commitments, albeit that the latter are associated with non-externalized states of mind and are not related with any speech acts (cf. Mackenzie and Staines 1999).

12 In argumentative practice, too, the arguers' orientation seems pragmatic rather than epistemological. Gaskins (1992, 25-26) observes that "for pragmatists truth is 'the evolving product of a properly constituted research community' and that, in a similar spirit, the authority and legitimacy of the (American) judicial process is based on the integrity of its procedures rather than any privileged access to truth."

${ }^{13}$ Walton and Krabbe $(1995,46)$ point at a favorable consequence of spelling out the rules of dialogue in the opening stage of the discussion: "Your commitment tends to be made more specific as well, for when precise rules of argument are spelled out, the means you can use to defend your point of view are narrowed down." 
respond to according to Johnson (1998). ${ }^{14}$ As a matter of course, critical questions are not equal to counter-arguments and they do not involve any burden of proof, however "serious" they may be.

The burden of proof has been discharged only when all relevant critical questions asked by the antagonist have been answered in a way that is deemed sufficiently thorough by the antagonist and no unanswered critical questions remain. Then, the required constellation of arguments has been advanced completely in the argumentation and the argumentation is accepted, so that Govier (1998) would speak of an "exhaustive case."

\section{Strategic maneuvering with regard to the burden of proof}

How about strategic maneuvering with the burden of proof? The strategic maneuvering by the parties will be aimed at strengthening their position as much as possible in all stages of the resolution process. Besides non-fallacious maneuvering, there can also be fallacious manipulation of the burden of proof. As Walton (1988) rightly observes, some fallacies "reflect subtle shifts in the burden of proof that can be powerfully effective, yet often go unnoticed." In view of the difficulty of determining whether the criteria for complying with the dialectical norms are in fact fulfilled, it is necessary to have a clear view of the various kinds of manifestations of strategic maneuvering with the burden of proof.

\section{Confrontation stage}

In the confrontation stage, the dialectical objective of the parties is to achieve clarity concerning the specific issues that are at stake in the difference of opinion and the positions of the parties involved. Viewed rhetorically, the parties aim to direct the confrontation in the way that is most beneficial from their own perspective. This means that each party will attempt to achieve a definition of the disagreement space that highlights the issues both parties want to discuss and that each party will attempt to create the positions they would like to be assumed. As far as the burden of proof is concerned, their strategic maneuvering will concentrate on acquiring the most expedient burden of proof - the maneuvering in the confrontation stage is preparatory to the actual assumption and division of the burden proof in the opening stage. In the confrontation stage, both parties can play a constructive and also a not so constructive part. In the first case, their strategic maneuvering results in a clear view of the preconditions for assuming and dividing the burden of proof; in the second case, it prejudges these matters.

The party who has a certain standpoint can act constructively in acquiring an expedient burden of proof by stating as precisely as possible what his position amounts to, thus avoiding any confusion about what exactly he is prepared to defend. One way of doing this is to make unequivocally clear in the presentation of the standpoint that its scope is limited in a specific way, so that no burden of proof can ensue for anything that exceeds this scope. The same effect can be achieved by leaving aside any issues that are known to be controversial in the discussion

\footnotetext{
14 The critical questions systematically associated with the use of particular argument schemes agree to some extent with the Standard Objections distinguished by Henry W. Johnstone Jr, which refer to a class of objections "typically or frequently found in the neighborhood of prominent issues," but, due to their association with particular argument schemes, critical questions are more general and more systematic.
} 
context but would interfere with a piecemeal engineering of the resolution process when taken into account. The admissibility of using such a technique in strategic maneuvering may depend on the text genre involved. In the case of an apologia, for instance, it seems clear that particular "accusations" need to be responded to - if not for dialectical reasons, then at least for social or moral reasons. ${ }^{15}$ The party that doubts the acceptability of the standpoint, or is inclined to contradict it, can play a constructive strategic part in construing the burden of proof by articulating what the nature of his criticisms is and to which aspects of the standpoint they exactly pertain. He can also articulate a strategic position in the discussion. An obvious way of achieving this is by stating immediately that he does not take a counter-standpoint on the topic, but is only interested in hearing reasons for the standpoint of the other party, so that he "plays it safe" and no burden of proof can be attached to his position.

Strategic maneuvering with regard to the burden of proof in the confrontation stage can also be fallacious. This is the case when the party who advances a standpoint tries to escape from acquiring a burden of proof. He can, for instance, do so by pretending that there is no real difference of opinion, thus avoiding a critical treatment of his standpoint. Techniques that can be used are phrasing the standpoint "hermetically" ("The Frenchman is essentially intolerant"), presenting something as a point of departure instead of as a standpoint, presenting the standpoint as self-evident ("It is clear that") or guaranteeing its acceptability in another way ("I assure you that"), and declaring the standpoint sacrosanct and making it immune to criticism. The critical party maneuvers fallaciously when he attempts to saddle the other party with an extra burden of proof. He can do so by attributing a burden of proof to the other party for a standpoint that the other party may be deemed to have but has not expressed and obviously cannot properly defend, exploiting what Gaskins $(1992,21)$ calls the "risk of non-persuasion." Another technique is making the other party prove that he does not have a personal interest in the standpoint he has advanced ("circumstantial ad hominem") or that his standpoint is not inconsistent with a view he has expressed earlier ("tu quoque").

\section{Opening stage}

The dialectical objective of the opening stage is to establish an unambiguous point of departure for the discussion. This point of departure consists of intersubjectively accepted procedural and material starting points - the mutual "concessions" - and also includes a division of the discussion roles. The rhetorical aim of each of the parties is to arrive at a point of departure that serves their own interest best. Since it depends on the allocation of discussion roles and the choice of starting points how expedient the division of the burden of proof will be and how easy it is to discharge, both parties' strategic maneuvering will be aimed at establishing the most opportune allocation of discussion roles and the most workable starting points. What the most opportune allocation of discussion roles is and what the most workable starting points are, are interrelated questions: the answer depends to a great extent on the argumentative duties a party is prepared to assume in view of the starting points the other party is prepared to accept, and, vice versa, on the starting points a party is prepared to accept in view of the argumentative duties the other party is prepared to assume.

\footnotetext{
${ }^{15}$ As Krabbe (1999) emphasizes, it is "not the question whether one should enter some discussion at all. This is not to deny that one may feel obligated to respond [...]."
} 
With respect to the division of discussion roles, the parties' constructive strategic maneuvering will amount to making a rhetorically advantageous choice that allows them to defend or attack exactly those points they see fit to defend or attack. If a party intends to take on the role of protagonist, this would-be protagonist's constructive maneuvering regarding the starting points will be aimed at establishing the strongest possible basis for defending his standpoint. To this end, he may, for instance, attempt to highlight those concessions of the would-be antagonist that suit him best. As Pinto correctly observes "questions of reasonableness of premises are intimately connected with the suitability of the inferences that can be made from them" (2001: xii). ${ }^{16}$ A way of achieving this emphasis is to make the other party's commitments, including the contextual commitments that can be attributed to him, transparent in the presentation, making those starting points explicit in the process that would otherwise remain obscure and could lead to superfluous discussion.

Strategic maneuvering on the part of the would-be protagonist becomes fallacious when he declines without a valid reason to take on the role of protagonist of a standpoint that he has advanced ("evading the burden of proof"). His maneuvering is also fallacious when he plays down his burden of proof, weakens it in his final presentation of the standpoint, or even "shifts" the burden of proof to the other party by acting as if the antagonist in expressing his doubt has acquired a burden of proof for the negation of the standpoint - or is in fact even the only one that has a burden of proof. Conversely, a party that acts as a would-be antagonist maneuvers fallaciously if he ignores a burden of proof for a contradictory standpoint that he has advanced. He can do so by representing a negative standpoint as merely an expression of doubt. He also acts fallaciously if he exaggerates the scope of the protagonist's standpoint, thus attributing a stronger burden of proof to the protagonist than is justified ("straw man"). A protagonist gets an easy chance to act fallaciously as a would-be antagonist when in a mixed dispute there is unclarity concerning the precise criteria for applying such principles as those of presumption (what is the prevailing status quo?) and fairness.

\section{Argumentation stage}

In the argumentation stage, the dialectical objective is to test the tenability of the standpoints that have shaped the difference of opinion in the confrontation stage, starting from the point of departure established in the opening stage. Viewed from a rhetorical perspective, the parties aim to make the strongest case and to launch the most effective attack. This means that the strategic maneuvering of the protagonist in regard of discharging the burden of proof will consist in bringing forward the argumentation that resolves the difference of opinion as quickly and thoroughly as possible. One way of doing this constructively is by construing an argumentation that reacts or anticipates optimally to the antagonist's opposition, responding first to those real or anticipated objections against his standpoint or the arguments advanced in its defense that Govier (1998) calls "the most telling" objections and that Krabbe (1999) specifies as those serious objections that would utterly refute the protagonist's position. In practice, the protagonist can also maneuver constructively by acknowledging objections other than he himself deems damning and advance multiple argumentation to accommodate these objections by separate lines of

\footnotetext{
${ }^{16}$ In this connection it is noteworthy that in law 'inadmissible evidence' does not automatically mean that a certain 'fact' is not correct but rather that the consequences that follow from this fact for the case at hand may not be drawn. Cf. Rescher 1977.
} 
arguments, making the abundance of his defense manifest in his presentation. ${ }^{17}$ Conversely, by advancing multiple argumentation he can also make clear that, even if a certain argument he himself finds convincing is not accepted as such, there are still other sufficient reasons to accept the standpoint. The constructive maneuvering of the antagonist can amount to creating the opposition that the protagonist finds hardest to deal with. When the dispute is non-mixed, this can be done by asking all the critical questions that are pertinent; when the dispute is mixed, by persistently advancing refuting objections. In the first case, the antagonist can critically question at the same time both the reason that is advanced and the argument scheme that connects this reason to the standpoint at issue, or concentrate on the one he expects the protagonist finds hardest to support, again taking advantage of the protagonist's obligation to produce such support and exploiting the protagonist's risk that providing inconclusive support will count against him.

The protagonist may in various ways maneuver fallaciously. He can, for instance, anticipate doubts or objections that are only of his own invention, address irrelevant objections or address relevant objections only partly, put forward irrelevant argumentation ("ignoratio elenchi") or argumentation that is only apparently relevant, and appeal to sources that are only seemingly authoritative ("argumentum ad verecundiam"). The antagonist, on his part, maneuvers fallaciously when he - pretending to be a radical critic - keeps repeating critical questions that have already been answered satisfactorily and for which the burden of proof has already been discharged.

\section{Concluding stage}

The dialectical objective of the parties in the concluding stage is to establish the result of the critical testing procedure and to decide jointly to what extent the burden of proof has been met. Can the protagonist maintain his standpoint in the light of the criticisms advanced by the antagonist? Or can the antagonist maintain his position of doubt even considering the arguments advanced by the protagonist? Viewed rhetorically, each party will attempt to claim victory and their strategic maneuvering will be designed accordingly. Constructive maneuvering by the protagonist may in this stage consist of emphasizing the elements that are part of the burden of proof that have been satisfactorily dealt with. The antagonist may maneuver constructively by emphasizing the points where some doubt can be maintained. A fallacious move by the protagonist would be to act as if his standpoint has been adequately defended while ignoring certain recognized shortcomings in his defense. He can also make an unjustified absolute of the success of his defense by claiming that his standpoint is true, instead of only proven tenable in the light of the antagonist's concessions and criticisms. The antagonist, from his part, would make a fallacious move if he acted as if the standpoint of the protagonist had been refuted while ignoring the protagonist's adequate responses. He would also maneuver fallaciously if he claimed that the protagonist's failure to defend his standpoint conclusively automatically proves the opposite standpoint to be correct ("argumentum ad ignorantiam"). Although this is not a reasonable move in a critical discussion, in some institutional or practical contexts where a final decision or immediate action is required, it is, due to circumstantial limitations, the only -

\footnotetext{
${ }^{17}$ This is, of course, Whately's observation: "It may often be expedient to bring forward more proofs than can be fairly demanded of you. It is always desirable, when this is the case, that it should be known, and that the strength of the cause should be estimated accordingly" (1846, III, 2, part I/p. 112).
} 
morally, practically or otherwise - justified way to proceed. From its use in these special contexts, this move may derive its rhetorical force.

How to react when the other party has maneuvered in such a way that a fallacy has been committed with regard to the burden proof? Just like they have the unconditional right to ask for a specification or elucidation and to provide such clarifications, both parties have in all stages of the discussion the right to accuse the other party of having committed a fallacy. This, however, is a conditional right, which can only be exercised if the accusation is at the same time substantiated. As Walton and Krabbe (1995) observe, "there is a serious burden of proof on the would-be critic who is to go around declaring arguments fallacious." This burden of proof may be difficult to discharge. More often than not such fallacies are, after all, committed in a concealed way, so that they can easily be denied. As van Eemeren and Grootendorst (1992) emphasized, fallacies are often hidden by implicit, vague or ambiguous language use or conveyed indirectly or through conversational implicatures. ${ }^{18}$ Also, in actual argumentative practice, the accused party will usually not be inclined to give in easily to fallacy criticism. Unlike in third party evaluation, again, a certain amount of strategic maneuvering may be needed to convince the other party (or other members of the audience) that a certain move is fallacious. One is then required to explain exactly which offense against critical reasonableness has been committed. Committing an outright "counter-fallacy" is, viewed from our perspective, in any case not an adequate response (cf. Jacobs 2000).

\section{Conclusion}

In the case of argumentation there is always a difference of opinion between people, "out there," in the real world - a difference that is, as it were, "waiting" to be resolved. In this paper, we have explained what a pragma-dialectical approach to argumentation in terms of speech acts, commitments, mutual coordination, and procedural rules amounts to in the analysis of the burden of proof. We have addressed the central questions of why there should be a burden of proof, to what it applies, to whom it is to be assigned, what it involves, under which conditions it is activated, by what means it can be discharged, and when it is met. We have done so in a critical rationalist vein, attuned to furthering the most systematic, perspicuous, economic and thorough process of resolving a difference of opinion by critically testing the tenability of a standpoint.

Because the management of the burden of proof, just like that of other relevant components of the discourse, is subjected to a potential tension between dialectical standards of critical reasonableness and the rhetorical aim of deciding the discourse in one's own favor, a clear view is to be achieved of the parties' strategic maneuvering. Although strategic maneuvering is inherent in argumentative discourse and often perfectly legitimate, there can also be occasional "derailments." We have shown for each stage of the resolution process how strategic maneuvering with regard to the burden of proof can be constructive and sound but also how it can deteriorate and become fallacious.

\footnotetext{
${ }^{18}$ Walton (1996) also identifies other specific techniques to disguise violations of the burden of proof rule: innuendo, say so, attribution, plausible denial of commitment, ambiguity, and other deceptive or confusing techniques.
} 


\section{References}

Albert, Hans. 1975. Traktat über kritische Vernunft. 3rd Ed. Tübingen: Mohr.

Barth, E.M. and E.C.W. Krabbe. 1982. From Axiom to Dialogue. A Philosophical Study of Logics and Argumentation. Berlin/New York: Walter de Gruyter.

Biro, J. and Siegel, H. 1992. "Normativity, Argumentation and an Epistemic Theory of Fallacies," In F.H. van Eemeren, R. Grootendorst, J.A. Blair \& C.A. Willard (eds.), Argumentation illuminated (p. 85103). Amsterdam: Sic Sat, 1.

Eemeren, F.H. van and R. Grootendorst. 1984. Speech Acts in Argumentative Discussions. A Theoretical Model for the Analysis of Discussions Directed towards Solving Conflicts of Opinion. Dordrecht/Berlin: Foris/Mouton de Gruyter.

Eemeren, F.H. van and R. Grootendorst. 1992. Argumentation, Communication, and Fallacies. A Pragma-Dialectical Perspective. Hillsdale, NJ: Lawrence Erlbaum Associates.

Eemeren, F.H. van and R. Grootendorst. 2002. Critical discussion. University Park, PA: Penn State Press.

Eemeren, F.H. van and P. Houtlosser. 1998. "Rhetorical Rationales for Dialectical Moves: Justifying Pragma-Dialectical reconstructions," In J.F. Klumpp (ed.), Argument in a Time of Change. Definitions, Frameworks, and Critiques. Proceedings of the tenth NCA/AFA Conference on Argumentation, Alta, Utah, August 1997, 51-56. Annandale, VA : National Communication Association.

Eemeren, F.H. van and P. Houtlosser. 1999. "Strategic Manoeuvring in Argumentative Discourse," In: Discourse Studies 1: 479-497.

Eemeren, F.H. van and P. Houtlosser. 2000a. "Rhetorical Analysis within a Pragma-Dialectical Framework," Argumentation 14: 293-305.

Eemeren, F.H. van and P. Houtlosser. 2000b. "Managing Disagreement: Rhetorical Analysis within a Dialectical Framework," Argumentation and Advocay 37: 150-157.

Eemeren, F.H. van, B. Meuffels and M. Verburg. 2000. "The (Un)reasonableness of the Argumentum ad Hominem," Language and Social Psychology 19: 416-435.

Goodnight, G. Th. 1980. "The Liberal and the Conservative Presumptions: On Political Philosophy and the Foundation of Public Argument," In J. Rhodes \& S. Newell (eds.), Proceedings of the [First] Summer Conference on Argumentation, 304-337. Annandale, VA: Speech Communication Association.

Govier, T. 1998. "Arguig Forever? Or: Two Tiers of Argument Appraisal,” In H.V. Hansen, C.W. Tindale and A.V. Colman (eds.), Argumentation \& Rhetoric (CD-ROM). St. Catherines, Ontario: OSSA.

Hamblin, C.L. 1970. Fallacies. London: Methuen.

Jacobs, S. 2000. "Rhetoric and Dialectic from the Standpoint of Normative Pragmatics," Argumentation 14: 261-286.

Johnson, R. 1998. "Argumentative Space: Logical and Rhetorical Approaches,” In H.V. Hansen, C.W. Tindale and A.V. Colman (eds.), Argumentation \& Rhetoric (CD-ROM). St. Catherines, Ontario: OSSA.

Johnson, R. 1999. "More on Arguers and Dialectical Obligations," Proceedings of the 1999 OSSA Conference.

Johnson, R. 2000. Manifest Rationality. Mahwah, NJ: Lawrence Erlbaum.

Krabbe, E.C.W. 1999. "Response To Ralph H. Johnson's 'More on Arguers and Dialectical Obligations'," Proceedings of the 1999 OSSA Conference.

Leff, M. 2000. "Rhetoric and Dialectic in the Twenty-First Century," Argumentation 14: 241-254. 
MacKenzie, J. and Ph. Staines. 1999. "Hamblin's Case for Commitment: A Reply to Johnson," Philosophy \& Rhetoric 32: 14-39.

Perelman, Ch. and L. Olbrechts-Tyteca. 1958. La nouvelle rhétorique. Traité de l'argumentation. Paris: Presses Universitaires de France.

Pinto, R.C. 2001. Argument, Inference and Dialectic. Dordrecht: Kluwer Academic Publishers.

Rees, M.A. van. 2000. "Comments on 'Rhetoric and Dialectic in the Twenty-First century'," Argumentation 14: 255-259.

Rescher, N. 1977. Dialectics. A Controvery-Oriented Approach to the Theory of Knowledge. Albany, NY: SUNY Press.

Toulmin, S. (1997). “A Dissenter's Life.” Thomas Jefferson Lecture, Washington, March 24, 1997.

Ullmann-Margalit, E. 1983. "On Presumption,” Journal of Philosophy 80: 143-163.

Walton, D.N. 1988. "Burden of Proof," Argumentation 2: 233-254.

Walton, D.N. 1996. "Plausible Deniability and Evasion of Burden of Proof," Argumentation 10: 47-58.

Walton, D.N. and E.C.W. Krabbe. 1995. Commitment in Dialogue: Basic Concepts of Interpersonal Reasoning. Albany, NY: State University of New York Press.

Wenzel, J.W. 1980. "Perspectives on Argument," In J. Rhodes \& S.E. Newell (eds.), Dimensions of Argument. Proceedings of the Summer Conference on Argumentation, 112-133. Annandale, VA: Speech Communication Association.

Whately, R. 1846. Elements of Rhetoric. Comprising an Analysis of the Laws of Moral Evidence and of Persuasion, with Rules for Argumentative Composition and Elocution. Facs. Ed. Douglas Ehninger 1963. London/Amsterdam: Southern Illinois University Press. 